\section{WISDOM FROM THE TORTOISE}

\section{Ruenruthai Sujjapun ${ }^{1}$}

\begin{abstract}
The Hare and the Tortoise Part II: We do not race anymore won the '7 Book Awards' of 2005 as the best work of children's literature. This book borrows its plot from a well-known Aesop's fable and creates some new content and philosophy. Instead of ignorantly running a race against the aggressive Hare, the Tortoise refuses to compete but rather walks slowly and happily to his destination. In addition to the plot from Aesop's fable, the writer H. Nikhooky applies Buddhist doctrines with regard to defilements, i.e., lust, greed, anger, and delusion, as well as the Four Sublime States of Mind or the "Brahm-Vihara4", i.e., kindness, compassion, sympathy, and equanimity in the many episodes during the long journey of the Tortoise family. Also, the book suggests that the best way of bringing people and the world to real happiness is through gratitude, forgiveness, consciousness, wisdom and sufficiency.
\end{abstract}

Though this book was written as a piece of children's literature, it provokes the reader's thoughts about the real world in which we live: a world full of competition in which winners like the arrogant Hare in this book are proud and happy to beat the

\footnotetext{
${ }^{1}$ Professor, Department of Thai and Oriental Languages, Faculty of Hamanities, Ramkhamhaeng University
}

losers. The Tortoise, on the other hand, leads us to realize that winning over oneself is the best and most beautiful way to lead our lives.

\section{Introduction}

The title of this article is inspired by a book named, The Hare and the Tortoise Part II: We do not race any more, written by H. Nikhooky. This book won the first prize in the ' 7 Book Awards' of 2005 in the best children's literature category.

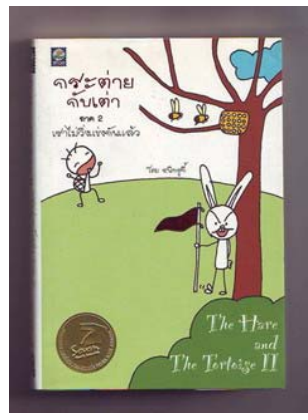

The author borrows the plot from one of Aesop's Fables, The Tortoise and the Hare, which is well known the world over. $\mathrm{He}$ reformulates the original fable by adding new ingredients containing Buddhist Dhamma doctrines to teach readers, children and adults alike, to maintain a good heart, kindness, and a preference for reconciliation rather than competition, in contrast to the prevalent mentality that presently dominates people in the material world.

\section{Aesop's Fables}

Aesop's Fables are part of the world heritage of ancient tales. Aesop, the storyteller, was a Greek who lived around 600 B.C. He is famous for his fables: short tales that illustrate truths about life and human nature. Most of his fables feature familiar animals, including The 
Grasshopper and the Ant and The Tortoise and the Hare. Little is known about the actual life of Aesop himself and some believe that no such person ever really existed. Those who believe Aesop existed generally agree that he lived during the 6th century B.C., for some time on the island of Samos and was, for at least part of his life, a slave, which could have been a result of his physical deformity. Aesop comes from the name "Ethiop" which means "black skin". Prince Adman, the governor of Samos Island, became his patron. Aesop became a counsellor and an expert at the court of King Crisus of Lydia. He was named "1 of the 7 sages" and eventually, Aesop was murdered. His fables are in the oral tradition. They were compiled after his death and were translated into Egyptian, Latin and Greek. In A.D.1400 they were translated into European languages such as English, German and Spanish and they spread throughout the world from then. According to Thanakit (1998), it is generally agreed that not all of Aesop's Fables were actually created by him but his fame grew so much that many other fables were eventually ascribed to him.

Aesop's Fables are short tales in which the behaviour of the animal characters demonstrates wisdom and conscience to the audience. Each fable usually ends with a conclusion that starts out with the famous line, "The moral of the story is -----", which is wisely employed to reemphasize the theme of each fable and link the story to the real world. For example, The Rat and the Lion presents the concept, "Never hold an inferior person in contempt. If you are good to him, one day he may reciprocate." A bad individual is depicted as one who never shows gratitude in The Farmer and the Snake. On the other hand, The Hen and the
Ruby portrays a nice thing that deserves to be cherished only by those who realize its value. The conclusions drawn from Aesop's Fables were taken from truths that have been tested by time. That is why Aesop's Fables are immortal and always modern.

As works of oral literature, Aesop's Fables were propagated from Ancient Greece to every corner of the world. His fables came to Siam along with the Indian tales in the Ayudhaya period during the reign of King Narai the Great. The fables were compiled into Thai and called, Aesop Pakoranam (the Aesop Mythology). In B.E. 2454, (A.D. 1911) in the Rattanakosin period, Somdej Krom Phraya Damrong Rajanuphab (Prince Damrong Rajanuphab) advised Phraya Methathipbodi to revise the fables by "employing easy language and short sentences in order to make it supplementary reading for students who have accomplished the prerequisite Mulasuksa text." (Methathipbodi 2000: 8) Prince Damrong Rajanuphab edited every fable himself before its publication. The book consists of 45 fables and some survive these days as reading material for elementary students. Apart from Aesop's Fables as revised by Phraya Methathipbodi, there are several versions that have been translated from English by others.

Among Aesop's Fables, The Tortoise and the Hare is one of the most famous. The tale depicts a Hare that laughs at a slow walking Tortoise. In turn, the Tortoise dares the Hare to race. Both animals ask a fox to pick the route and to pass judgment. On the day of the race, the Tortoise walks at his earnest pace, step by step, little by little, until he finally arrives at the finishing line. In contrast, the over- 
confident Hare is so complacent of his running prowess that he carelessly falls asleep on the route. After waking in alarm, he speeds as fast as he can but finds that the Tortoise has already won the race. Complacency has led the Hare to his downfall in the race. Phraya Methathipbodi concludes at the end of the fable that, "This fable teaches that one should not underestimate others who seem to be inferior. It is a disgrace when those whom you look down upon prevail." (Methathipbodi 2000: 31). Apparently the fable discourages us from being arrogant in our overconfidence and insulting others. It also preaches perseverance, suggesting that one born inferior yet possessing perseverance may realize his goals sooner or later.

\section{Dynamism of the tale of The Tortoise and the Hare}

Aesop's adapted fables have been adopted as school reading material for nearly a century. Ever since the Thai education reforms and the advent of modern educational management during the reign of King Chulalongkorn or King Rama V (A.D. 1869 - 1910), The Hare and the Tortoise $^{2}$ has taken its place in the minds of Thai people as it is always cited whenever perseverance and humility are mentioned.

Today, The Hare and the Tortoise has been recreated as The Hare and The Tortoise Part II: We do not race any more and it, also, remains an outstanding example of children's literature that

\footnotetext{
${ }^{2}$ This fable was entitled in English "The Tortoise and the Hare" but when it was translated into Thai, this fable was entitled "The Hare and the Tortoise".
}

reveals the dynamism of the original fable by Aesop.

This work of children's literature changes and enhances the plot originally presented in Aesop fable. We can see that $\mathrm{H}$. Nikhooky has refashioned the story of The Hare and the Tortoise by altering the tale and enhancing the content of the story in many respects. Certain features worth mentioning include the following:

\section{Expanding the body of the story.}

The Aesop fable recounts the short story of a tortoise that dares a hare to race because he is angry for being held in contempt by the hare who belittles him. $\mathrm{H}$. Nikhooky expands the story with many details in his novel, they are

The Long Journey of the Tortoise Family

A family of tortoises, consisting of the father, the mother and two sons, is migrating to a new swamp because the water in its old neighborhood is drying up. No kind of aquatic animal and amphibian can live there any longer. The baby tortoises feel sympathy for the fish and they ask their father to carry the fish to the new swamp. Father Tortoise tells his children that they will all die before reaching their destination. He also teaches his children that sympathy and assistance provided for others are all well and good if the helper himself is not in trouble, otherwise one has to be content with the sense of powerlessness one is dealing with. 


\section{Meeting a Prisoner}

During their 10-kilometre journey to the new swamp, the Tortoise family meets a prisoner who has been condemned to be executed. One of the baby Tortoises wants to rescue him but his father forbids it. He tells the baby Tortoise that the prisoner deserves to die because of his crime. $\mathrm{He}$ also teaches his children to exercise self-control, so that their sympathy towards assistance for others is objective and discrete in the appropriate circumstances.

\section{Meeting an Arrogant and Bullying} Hare

During the long journey they encounter a passing big white hare. The Hare laughs at and mocks the slow walk of the Tortoise family. He calls them snails and sarcastically says that the Tortoise family might reach the swamp in their next life. The Hare dares the Tortoise to race in order to avenge his ancestor who had been defeated in the old days. The Tortoise refuses to compete. The children urge their father to race but the father says that he will not let ignorance and anger spoil his mind. The Hare insists so many times that the Tortoise admits defeat. The Hare does not accept this and starts running daring the Tortoise to go after him. A child Tortoise runs out of patience and asks permission from his father to race against the arrogant Hare instead but this is refused and, so, the child obeys.
The Tortoise Rescues the Hare

Finally, the Hare is trapped by a hunter. His legs are tied with a rope hung from a tree and his head dangles in the air. The Hare begs the Tortoise to bite through the rope but before lending him a hand, the Tortoise asks for a promise from the Hare that he will behave. The Hare gives his vow but upon being released, swallows his words and runs away. The Tortoise family continues its journey. The Hare is later found to have been trapped again. This time the Tortoise saves the Hare's life without asking for any promises. For he concludes that, if the Hare does not want to be good, that is his own business.

\section{Encountering a Wolf}

On continuing the journey, the Tortoise family encounters a wolf. Father Tortoise tells his family members to hide their heads inside their shells. The Wolf tries to lure the tortoises to stick their heads out of the shells but the trick does not work. The Wolf tells them that a Hare has advised him to catch the foolish tortoises. In return, the Tortoise tells him about the wicked Hare. After the Wolf learns the truth, he is so angry that he wants to kill the Hare instead. One of the baby tortoises wants to tell the Wolf how to catch the Hare but his father tells him not to commit a sin. The Wolf offers the Tortoise a deal that will save his family if only he will sacrifice his life. The Father is willing to do so but his family will not let him. 
They say that, if the Father Tortoise lets the Wolf eat him, they will do the same. Therefore, all the tortoises hide their heads in their shells all day and all night until the next day. The Wolf witnesses their endurance and their strong belief in morality. He leaves without harming the tortoises and also blesses them for holding on to their virtue.

The Tortoise Makes the Decision to Race the Hare

The Tortoise family meets the Hare at the roadside again. The Hare threatens that if the Tortoise does not race he will tempt the Hunter to catch the Tortoise. This time the Tortoise decides to race in order to save his family. After the Tortoise has made his decision, the Hare runs ahead very fast. The tortoises, on the other hand, keep walking towards the swamp, ignoring the race. Victory or defeat is not important to them for if they can reach the swamp, they will have prevailed. They win over themselves by the virtue of endeavour.

The Tortoise and the Hare Make Friends

After walking for a while, the Tortoise meets the Wolf waiting for the Hare who is hiding in the bush. The Hare tells the Wolf to eat the Tortoise instead. That makes the Wolf even angrier and he reprimands the ungrateful Hare. The Wolf tells the tortoises to keep on with their journey while he will wait to catch and eat the
Hare when the latter comes out from the bushes or he will howl out loud until the Hunter comes to hunt the Hare. The Tortoise feels very sympathetic and he tries to save the Hare's life by convincing the Wolf to do good deeds and not harm others. The Tortoise preaches to the Wolf from dusk till dawn until the Hare who is listening to every word feels guilty. He is so impressed by the Tortoise's virtue that he comes out of the bushes and is going to let the Wolf eat him. The Wolf appreciates both the Tortoise's kindness and the Hare's repentance so much that he leaves them unharmed. So, the Tortoise and the Hare become friends. They walk together without racing from then on. There is neither a winner nor a vanquished. Both are at peace.

Friendship between the Tortoise, the Hare and the Wolf

Finally, the tortoises and the Hare meet the trapped Wolf, hanging from the tree and dangling in the air. The Tortoise saves the Wolf's life. The Wolf confesses to them that he had been waiting at the roadside to catch and eat the Hare and the tortoises. Now he realizes that suffering belongs to those who cause others to suffer. Because of his rescue by the Tortoise and the Hare, he promises not to kill tortoises and hares throughout his life nor any other animals. He also pledges not to eat meat, except for that which is already dead. 
Happiness at the New Swamp

Later on, they all travel to a swamp where the fertile ground and surroundings are the habitat for several kinds of aquatic animals and amphibians. Seeing that the Tortoise family is living happily, the Hare and the Wolf bid them farewell.

\section{Alteration of the content.}

The original story tells that the Tortoise is the one who dares the Hare to race after he is mocked for his short legs. The Tortoise can win the race because of his exertions and because of the Hare's complacency when the latter falls asleep happily while the Tortoise walks past him to the finishing line. H. Nikhooky critically alters the story so that the Tortoise is adamant not to race against the Hare. After the Hare has insisted many times, he admits defeat but the Hare will not accept the winning so easily. He threatens to kill the Hare's family. Although it seems foolish, the Tortoise eventually accepts the challenge in order to save his family. Nevertheless, the Tortoise does not intend to win the race, so he walks slowly while the Hare run ahead very fast. The Tortoise just wants to proceed to his destination, i.e., another swamp.

\section{Adding new characters}

In Aesop's fable, there are only 3 characters: a tortoise, a hare and a fox. H.Nikhooky adds three more creatures and two characters: the Tortoise's wife, his 2 sons, the Hunter, and the Prisoner. He also touches on aquatic creatures like fish and the amphibians. The additional characters do not take an important role except for the child tortoise who is the narrator.
Nevertheless, they are supporting characters who portray the characteristics of the main characters which are the Tortoise, the Hare and the Wolf. The Tortoise is the father who has to protect his family from danger. $\mathrm{He}$ is able to die for his family as well as his family being able to die for him. The Father Tortoise always teaches his sons to think well and do well. He teaches his little son to apply reason and not passion in the case when his son wants to rescue the fish and the Prisoner. The Prisoner as well as the Hunter are just mentioned without any action. The Hare in the novel is a bully and is arrogant like the one in Aesop's fable but he is also wicked. He lies, he cheats, he is ungrateful and he tries to put the Tortoise to death. He wants revenge for his ancestor and to restore his reputation. Anyway, after realizing that the Tortoise is a really good individual, the Hare feels guilty and changes into a good one too. The Fox in Aesop's fable becomes a wolf. In the fable, the Fox is simply the one who chooses the racing route and the judge. In the novel, the Wolf takes a more important role. He is the one who tests the love in the Tortoise family and their endurance. At the end of the story, he is trapped while he is lying in wait to catch and eat the Tortoise family. After the Tortoise saves his life, he promises not to eat live animals anymore. Therefore, the Wolf as well as the Hare are additional characters that expand the role of the Tortoise and illustrate his character.

\section{Changing the theme.}

The original theme of this Aesop's fable lays emphasis on failure as the result of underestimating an opponent, as well as success as a reward of endurance. $H$. Nikhooky changes the moral of the story to suggest that winning over oneself is 
greater than conquering others, for overcoming one's own mind is very difficult. This work of children's literature introduces many Buddhist Dhamma doctrines such as, Anger should be conquered by non-anger, Revenge should be ended by forgiveness, Helping others without troubling oneself, Ending vengeance by avoiding revenge, etc. These Buddhist Dhamma doctrines shall be explained later.

\section{Wisdom from a tortoise}

The Hare and the Tortoise Part II: We do not race anymore has been created as a work of Thai children's literature. The lovely illustrations in the book are attractive to children. Each page contains only a few sentences and this makes it appealing and easy to read and understand. Actually, The Hare and the Tortoise Part II: We do not race anymore is not only children's literature but also Dhamma or religious prose. The author introduces Buddhist Dhamma views into the tale to offer readers some elements of the oriental beliefs.

H. Nikhooky is the pen name of Phitak Saingam who was a monk for many years at Wat Thepsirintharavas . After leaving the monkhood, he became a writer. Some of his books present the concepts of Dhamma, for instance, The Breeze of Dhamma (prose), Dhamma of Thaksin Shinawat (prose), The Flag of Buddhist Socialism (poetry), I am God (novel), and The Hare and the Tortoise Part II: We do not race anymore.

The Dhamma principles presented in this children's book are down to earth and can be applied to activities in everyday life. These doctrines are represented by the words that Father Tortoise speaks to his sons, the Hare and the Wolf. Some examples will be analyzed to indicate the Buddhist doctrines and are demonstrated below:

\section{1. "If we help them, then we are in trouble; we should not do that." (Nikhooky 2004: 17)}

The Tortoise teaches his sons that helping others should not bring trouble on oneself. Buddhist doctrine teaches us that kindness should be applied with wisdom. Sympathy without awareness can bring trouble on oneself as well as others. Therefore, the Tortoise does not carry the fish along to the new swamp since the overloaded burden can kill the tortoises as well as the fish. On the contrary, the Tortoise rescues the Hare and the Wolf, his enemies, because he can do it without difficulty and, also, he does not want anything in return except for satisfaction and happiness. These words emphasize the importance of reason rather than passion.

\section{2. "Every life ends with death." (Nikhooky 2004: 27)}

This sentence is from the teaching about the mindfulness of death. In this work of children's literature, the fish in the dry swamp acknowledge death peacefully and they share the joy of seeing that the Tortoise family will survive in the new swamp. When the Tortoise is threatened by the Wolf to sacrifice his life to save his family, the Tortoise is willing to 
do so as are his family for him. Therefore, the awareness that every life will come to the end sooner or later lets man face bravely his destiny and also live happily.

3. "That Hare is so bad, ungrateful, and harmful to his benefactor. The fruit of his sin will return one day." (Nikhooky 2004: 156)

This sentence is the same as the Buddhist saying that gratitude is a sign of goodness. In the book, the Hare is ungrateful even though the Tortoise saves his life many times. The Hare tells the Wolf to catch and eat the Tortoise. The Wolf lies in wait to kill the Tortoise but he is trapped instead. The book also indicates the Law of Karma. After the Tortoise has saved him from the trap, the Wolf feels guilty and full of gratitude. He promises to behave and do good deeds, uphold morality and avoid killing. The Hare, the Tortoise, and the Wolf become friends from then on.

4. "If we are in despair, or too discouraged to move on, we will not reach our destination. If we walk earnestly without discouragement, we shall achieve what we want one day." (p. 39)

"To arrive sooner or later or not at all, is not the issue. What really matters most is exerting oneself." (Nikhooky 2004: 61)

Exertion is a noble virtue. The Buddhist saying, Trouble can be overcome through exertion is comparable to the Western proverb that says, Where there is a will, there is a way. The concept of Aesop's fable on the exertion of the Tortoise is maintained in the book. The Tortoise teaches his family to believe in this virtue. Walking 10 kilometres to a new swamp is the lesson learned by this principle. The exertion required to save the life of his enemies again and again, the exertion to teach enemies to do good deeds and uphold morality and the exertion to change enemies into friends are portrayed in the book to convey a lesson to the readers. Perseverance ushers the Tortoise family to its goal. If we exert ourselves to do something, we will reach our goal too.

5. "Rather than trying to defeat others, we should win against ourselves." (Nikhooky 2004: 93)

H. Nikhooky emphasizes abandoning competition because a winner today may be a loser tomorrow or vice versa. Craving for victory induces a lust for gain and one can turn selfish and unforgiving. According to the story, the Tortoise does not want to race against the Hare and lets the Hare win instead. Not being obsessed with overcoming others, instead, being able to control himself is achieving the greatest victory.

6. "Even though he feels pity for the fish, he must exercise selfcontrol. He must not allow his 
compassion to ruin his life." (Nikhooky 2004: 47)

Kindness, compassion, sympathy and equanimity are BrahmaVihara 4 (the Four Sublime States of mind) which one should practise. Kindness means love and the desire for others to be happy. Compassion means pity and wishing to save others from their suffering. Sympathy means the gladness over the success of the others. Equanimity is a neutral feeling, not being overwhelmed with emotion, justice, not pained with the suffering of the others. ${ }^{3}$ We can deduce that the Tortoise believes in "Brahma-Vihara 4", for we can see that he loves all fellow beings, friend and foe. He feels pity when those beings suffer or their lives are in danger. He will help those in danger so long as the deed does not pose a danger to him. When he cannot lend a hand, he simply lets go. He shall never get himself into trouble and suffer as a consequence. He shall always be pleased to see others freed from suffering. As a believer in Brahma-Vihara 4, he teaches his sons to follow this Buddhist Dhamma, too.

\section{7. "Suffering belongs to those who cause others to suffer"} (Nikhooky 2004: 119, 249)

This is what the Tortoise tells the Hare. The Wolf also says the same to himself. According to the story, the Hare and the Wolf wait at the roadside to catch the Tortoise for

${ }^{3}$ From Pradharmkittiwongse (2005, p. 25,634, 790, 794, 1389) their lunch but both of them are trapped by the Hunter.

Both situations represent the Law of Karma ${ }^{4}$, or the Law of Cause and Effect. When the Hare and the Wolf intend to commit bad deeds, this immoral intention alone is the cause that quickly brings adverse effects. Both of them barely escape death saved only by the Tortoise.

\section{8. "He reaps what he has harvested." (Nikhooky 2004: 88)}

This saying directly refers to the Law of Karma. A Buddhist maxim says in Pali and Thai that

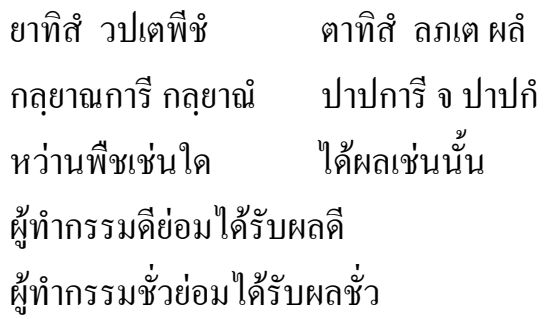

The Tortoise talks to one of his sons after the son asks him to save a prisoner's life. He does not do so but instead reminds the son to pity the victim of the prisoner as well. The prisoner must be punished in keeping with the crime he has

\footnotetext{
${ }^{4}$ While 'Karma' (Sanskrit) literally means the deeds that one commits, the Law of Karma extends to the eventual results brought about by the deeds. In Buddhist tradition, the deeds committed even immediately at the past moment are generally regarded as Karma from the past life, whereas the resulting effects could be realized in this or the next life, i.e., either immediately at the next moment or in a distant future.
} 
committed. Though we may have compassion for the prisoner we must let the Law of Cause and Effect take its toll.

Father Tortoise also talks about past and present Karma. When his son asks why the Hare will not stop bothering them, the Father explains that in the old days the Tortoise shamed the Hare. This might be his past Karma. He also says that, even though the past Karma exists, it is not as important as the present one. If we do good deeds, the present Karma can save our life. So we can see that the Wolf does not kill the tortoises because he is impressed by their virtues. The Tortoise tells his sons about the power of goodness, "If we do good deeds, no matter how harmful they are to us, the good deeds will always protect us." (p. 185). The didactic words of the Tortoise reflect the Law of Karma that says, "Doing good yields good results, doing bad yields a bad outcome."

9. "If you are angry with someone whom you consider bad because he displeases you, then you are as bad as him. Whether one is good or bad, let that be his business. We should not be bad like him." (Nikhooky 2004: 89)

When the Hare provokes the Tortoise into accepting his challenge, the Tortoise does not let anger possess his mind. When his son urges him to fight, he teaches his son not to let the emotion eclipse wisdom and commit evil. His thought is in agreement with the Buddhist saying that goes, "Anger should be overcome by not being angry", or, "Evil should be conquered by goodness". The Tortoise has strong willpower. $\mathrm{He}$ believes firmly in goodness and has never been affected by any kind of emotion.

\section{0. "We would rather die than}

\section{harm someone." (Nikhooky 2004: 175)}

The Tortoise family declares their stance that they would rather die than tell the Wolf how to catch the Hare. The Wolf is surprised that the tortoises save the Hare's life in spite of the fact that he is so ungrateful. The tortoises keep hiding in their shells under the hot sun all day long until the Wolf gains admiration for them. $\mathrm{He}$ is so impressed by their kindness that he cannot kill them. The Wolf leaves and urges them to maintain their goodness forever. Therefore, this sentence shows how the Tortoise follows the first Buddhist doctrine of five precepts.

We can conclude from these 10 examples that H. Nikhooky has the intention of teaching Buddhist doctrine to his readers through this children book. Many Buddhist doctrines are mentioned directly or indirectly; these are gratefulness, exertion, the four sublime states of mind, the law of karma, self-control, anger control, good deeds and bad deeds etc. We can see that the writer sincerely wants to explain the threefold method of training or the Tri Sikkha which are morality, concentration and wisdom. The Father Tortoise believes in virtue. He has the 
awareness not to commit wrongdoing and not to be aroused by temptations, therefore he has the wisdom to realize that winning someone is not worth more than winning over oneself. He knows what is the real happiness of life. He also saves the others from suffering and helps them to live happily.

\section{From Fable to Real Life: dynamism and wisdom in our contemporary society}

The journey of the Tortoise family can be related to the journey of everyone's life. The saying that life is a journey is appropriate. During each journey, one may have many aims. In the end, everyone shares a common destination, "death", whether one likes it or not. Therefore, a life that is useful and worthy of oneself and others is most important. Greed, anger, and delusion are enemies that destroy one's life. Man claims that he is a noble being; in fact he has more defilements than any kind of animal. The animal characters in Aesop's fables are an analogy for human beings. The behaviour, the emotions and thinking of the animals in Aesop's Fables are indeed, the reflection of human beings. As long as man is enveloped in the sea of defilements, the Aesop's Fables will serve well to teach us the truth of life. Therefore, almost all of Aesop's fables are dynamic and they are always up to date. However, some ideas can be adapted and considered from another aspect.

We are now in a world of competition, overwhelmed by a consumer culture. People aim at defeating others in order to excel and this comes at the expense of developing selfishness, lack of kindness, taking advantage of others to amass benefits for oneself and leaving no room for a mind that conceives of service. The theme of Aesop's fable not to underestimate opponents still works today but if we think of it from a different aspect; no more competition, then what will the world be like?

The Hare and The Tortoise Part II: We do not race anymore by $\mathrm{H}$. Nikhooky is a work of contemporary literature that refashions an old fable into a modern one. The book emphasizes the idea of the "acceptance of the status quo": that there are no winners or losers when there is no competition. Without competition, those defilements which are love, hate, greed, anger, obsession, lust, desire etc., will decrease. We will be able to say that everyone is a winner because he wins himself. Therefore, everybody will be happy in the same world. The Tortoise demonstrates to the Hare and the Wolf that compassion, which means the desire to make others happy, is a noble virtue. Thus, the Tortoise helps anyone who is suffering regardless of whether he be a friend or foe. The Tortoise shows us that we have to continue conducting ourselves morally because good deeds will shield us from evil and troubles. Our life will then be happy and we shall prosper.

This book also portrays gratitude, forgiveness, consciousness, wisdom, sufficiency and the Four Sublime States of Mind Brahm-Vihara 4 as the best way of bringing people and the world to real happiness. As they are analyzed in the last section, the Father Tortoise is not angry with the Hare and the Wolf, he always forgives them even though they show ingratitude and try to kill the Tortoise family. The Tortoise loves all creatures. $\mathrm{He}$ is kind and saves his enemies' lives again and again. He is pleased when they 
are saved from their suffering and change into good individuals. Also, he does not suffer when he can not help others due to their destiny. He believes in the law of karma too. The long journey of the Tortoise family causes happiness because they travel with Dhamma. Thus, Dhamma is the best companion throughout the journey of our lives. Besides enjoyment, the reader will gain wisdom from this children's book.

\section{References}

Methathipbodi, Phraya. 2000. Aesop's Fables. Bangkok: Thanpanya Publishing.

Nikhooky, H. 2004. The Hare and the Tortoise Part II: We do not race anymore. Bangkok: Dokya 2000 Publishing.

Pradharmkittiwongse. Kham Wat. 2005. Bangkok.

Thanakit. 1998. Immortal

Fables. (อมตะนิทาน) Bangkok:

Suwiriyasarn. 